\title{
CUATRO MODOS DE DEBATIR *
}

\author{
Josep Aguiló Regla \\ Universidad de Alicante
}

RESUMEN. El trabajo trata de exponer cuatro modos (tipos ideales) de debatir, de argumentar dialogando. Individualizados y ordenados a partir de la variable conflicto/cooperación, los cuatro modos de debatir son los siguientes: la disputa (debate conflictivo y actoral), la controversia (debate conflictivo y temático), el diálogo racional (debate cooperativo y temático) y el consenso (debate cooperativo y actoral).

Palabras clave: Modos de debatir, tipos de debate, debate, disputa, controversia, diálogo racional, consenso.

\section{Four Types of Debating}

ABSTRACT. The paper tries to expose four types (ideal types) of debating, of arguing through dialogue. Individualized and organized along the conflict/cooperation dimension, the four types of debating are the following: dispute (conflictive and actoral debate), controversy (conflictive and thematic debate), rational dialogue (cooperative and thematic debate) and consensus (cooperative and actoral debate).

Keywords: Types of debating, types of debate, debate, dispute, controversy, rational dialogue, consensus.

* Fecha de recepción: 28 de octubre de 2013. Fecha de aceptación: 25 de noviembre de 2013.

Este trabajo ha sido realizado en el marco del proyecto de investigación «Argumentación y constitucionalismo» (DER2010-21032), financiado por el Ministerio de Ciencia y Tecnología español. 


\section{INTRODUCCIÓN}

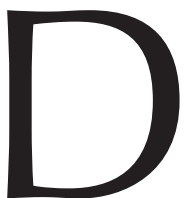

ebatir es argumentar en forma de diálogo. Naturalmente no en todos los diálogos la argumentación tiene el mismo peso. Hay muchos diálogos cuyo sentido no gira en torno a dar y quitar razones en defensa de tesis, acciones, afirmaciones o creencias. En este texto me propongo exponer cuatro modos de debatir, es decir, cuatro modos de argumentar dialogando. Ahora bien, antes de proceder a dicha exposición quiero dejar claras tres cosas que me parece importante advertir. En primer lugar, la finalidad que persigo no es, en realidad, intervenir en las eruditas discusiones académicas relativas a los géneros del debate propias de los estudios de dialéctica y de retórica. El análisis que aquí presento es, en este sentido, mucho más modesto y, además, responde a necesidades estrictamente instrumentales. En efecto, los cuatro modos de debatir tal como aquí se han perfilado pretenden resultar útiles en relación con un proyecto más amplio en el que estoy inmerso y que involucra la argumentación, la negociación y la mediación ${ }^{1}$. El carácter instrumental de dicho análisis no impide sin embargo pensar que lo que aquí se va a decir a propósito del debate pueda resultar útil más allá del ámbito del referido proyecto.

En segundo lugar, y a efectos de contextualizar el discurso sobre los modos de debatir, conviene apuntar siquiera la idea general que inspira ese proyecto más amplio. La idea es esta: Entender bien la mediación supone entender bien la negociación; y entender bien la negociación supone entender bien los aspectos argumentativos presentes en la misma. Por ello, los modos de debatir que voy a destacar tienen que resultar fácilmente reconocibles como propios, e incluso típicos, de diferentes fases posibles en una negociación. Para que un proyecto así resulte viable hay que aceptar tres presupuestos. El primer presupuesto es que si bien la negociación no es reducible a diálogo, sí puede decirse que sin diálogo, la negociación resulta inconcebible. Toda negociación implica diálogo ${ }^{2}$. El segundo presupuesto que hay que aceptar es que el

1 Este artículo reproduce -imagino que con pocas variaciones - una parte del texto que será el cap. II de un libro que estoy elaborando y cuyo subtítulo será (el título todavía no está decidido) «Argumentación, negociación y mediación». En el cap. I del referido libro, siguiendo la distinción propuesta por AtIENZA entre la concepción formal de la argumentación, la material y la pragmática (M. ATIENZA, El Derecho como argumentación, Barcelona, Ariel, 2006, 61 y ss.; y también, Curso de argumentación jurídica, Madrid, Trotta, 2013,107 y ss.), se muestra que para analizar adecuadamente las relaciones entre argumentación y negociación hay que situarse en el dominio de la concepción pragmática de la argumentación; donde la argumentación es contemplada esencialmente desde la perspectiva de la relación entre los sujetos de la argumentación. De este modo, «argumentación»y «negociación» comparten la noción de «relación social» como género común.

2 Algunos expertos en negociación hacen un uso idealizado de la palabra «diálogo», de forma tal que dicha noción aparece como opuesta a la de «negociación». Este es el caso, por ejemplo, de J. R. DE PÁRAMO, que de manera bien sucinta estipula de la siguiente manera la tesis de la separación entre «diálogo» y «negociación»: «Cuando alguien acepta el diálogo con otro sujeto reconoce su capacidad de argumentar y la posibilidad de verse atrapado por sus razonamientos y convertirse a su causa. El diálogo implica asumir la condición del otro como un sujeto que actúa conforme a razones, aceptar el compromiso de escucharlo y reconocer que es posible que tenga razón en sus apreciaciones [... Por el contrario,] negociar es un proceso entre las partes de un conflicto que tiene como objetivo la resolución de éste mediante la conformación de un acuerdo que se constituye a partir de la interacción entre las propuestas de solución que cada una de ellas presenta en la mesa. Los fundamentos del acuerdo son la voluntad de las partes y su nivel de satisfacción con respecto a las expectativas que tengan los negociadores. Es una estrategia voluntaria de adaptación y equilibrio, un método inteligente 
diálogo que tiene lugar en una negociación tiene un alto contenido argumentativo; en consecuencia, el diálogo propio de una negociación es un debate. En toda negociación, como mínimo, cada parte trata de persuadir — con razones o no ${ }^{3}$ - a la otra parte para que cambie o modifique sus posiciones o pretensiones iniciales. El tercer presupuesto que hay que aceptar parte del dato de que tanto debatir como negociar son actividades que implican al menos a dos sujetos que interactúan entre sí; es decir, dos sujetos cuyas conductas se condicionan recíprocamente, dos sujetos que se hallan en una situación de interdependencia. Solo metafóricamente pueden entenderse frases del tipo de «estoy negociando conmigo mismo» o «Luisa está dialogando/debatiendo sola». En consecuencia, tanto la negociación como el debate pueden conceptualizarse como «relaciones sociales». Como es bien sabido, en función de la compatibilidad o incompatibilidad de los objetivos perseguidos por los sujetos que interactúan, las relaciones sociales en general pueden clasificarse en relaciones cooperativas (de cooperación) y conflictivas (de conflicto). Pues bien, el tercer presupuesto es que la variable cooperación/conflicto juega un papel fundamental en la comprensión tanto del debate (y sus formas) como de la negociación.

Finalmente, y en tercer lugar, conviene advertir que los cuatro modos de debatir que voy a exponer están directamente inspirados por la lectura de la obra de A. CATTANI Los usos de la retórica ${ }^{4}$. Ahora bien, lo que viene a continuación no es una exposición de las tesis de CATTANI relativas al debate ni tampoco una aplicación de las mismas; exponer y aplicar exigen un grado de fidelidad a la «fuente» que yo no voy a practicar.

\section{DEBATIR ES...}

Debatir es — ya lo hemos dicho- argumentar en forma dialogada y, por definición, exige al menos la intervención de dos sujetos. Las figuras dialécticas conceptualmente próximas al debate son muchísimas. Por ejemplo (la siguiente relación en absoluto pretende ser exhaustiva): controversia, polémica, disputa, discusión, indagación, exploración, deliberación, diatriba, contienda verbal, tertulia, diálogo racional, entrevista, trato, etc. Ante tantos conceptos próximos, de tan difícil precisión y casi imposible distinción unos de otros, ¿`cómo proceder?

Para huir del ruido y del desconcierto, recurramos a las metáforas como forma de iniciar la tarea de composición de tipos ideales de debate. Consideremos las siguientes cuatro:

1. Debatir es combatir. Metáfora bélica.

2. Debatir es competir. Metáfora deportiva.

para asignar o repartir recursos, integrar eficientemente intereses y preferencias relativamente divergentes entre sí y dirimir el conflicto de una forma cooperativa [...]», J. R. DE PÁRAMO, «Carta abierta al Sr. Ministro de Educación», Nuevatribuna.es, 6 de junio de 2012. Naturalmente, aquí no voy a asumir una concepción del diálogo tan idealizada como la que refleja el texto de J. R. DE PÁrAmo.

3 Con la palabra «razones» ocurre algo muy semejante a lo que sucedía con la palabra «diálogo»; pues «razones» es susceptible de recibir también una interpretación idealizada de manera que aluda exclusivamente a las razones de corrección, a las razones últimas, imparciales...

${ }^{4}$ A. CatTAni, Los usos de la retórica (trad. J. LinARES), Madrid, Alianza Editorial, 2003. 
3. Debatir es explorar y/o diagnosticar. Metáfora médica.

4. Debatir es construir. Metáfora constructiva ${ }^{5}$.

A continuación, trataré de perfilar cada uno de estos modos de debatir en la confianza de que nos resulten fácilmente reconocibles (proyectables sobre la realidad) y distinguibles unos de otros. Para proceder a su caracterización pondré algunos ejemplos que puedan operar como paradigmas y trataré de explicar cosas tales como el tipo de relación que se da entre los sujetos que debaten, la finalidad que persigue cada uno de ellos, algunos resultados posibles y las reglas, formales e informales, que rigen en cada uno de esos tipos de debate. Esto último será muy importante porque permitirá mostrar que las falacias que pueden cometer los interlocutores variarán según el tipo de debate en que se hallen involucrados, es decir, la noción de falacia será relativa al tipo de debate, al modo de debatir.

Pero antes de entrar en todo ello, quiero llamar la atención sobre dos cuestiones que van a resultar de la máxima importancia. Primera cuestión; he evitado empezar poniendo un nombre a cada tipo ideal de debate. La razón para esta elusión es que la distinción de los modos de debatir es relativamente clara, pero la asignación de los nombres resulta altamente controvertida y problemática. Por ello, para evitar que la elección de las palabras bloquee la discusión de las ideas, he decidido aplazar hasta el final del texto la asignación de los nombres. Los introduciré en un cuadro que es una sistematización general de los modos de debatir. Segunda cuestión; la ordenación de estos cuatro modos de debatir no es azarosa ni caprichosa, responde a un criterio bien definido: Están ordenados a partir de la variable conflicto/cooperación entre los interlocutores ${ }^{6}$. Así, mientras que «1» representa el nivel mayor de conflicto, «4» representa el mayor nivel de cooperación. En consecuencia, «2»y « $33 »$ son graduaciones que representan respectivamente un descenso en la intensidad del conflicto y de la cooperación. En este sentido, «1» $\mathrm{y}$ «2» son formas conflictivas de debate y «3» $\mathrm{y} \ll 4 »$, formas cooperativas ${ }^{7}$. Es importante darse cuenta de que entre $\langle 2 » y$ « $\langle 3 »$ queda un espacio intermedio que no representa un término medio entre el conflicto y la coope-

5 Cattani distingue los siguientes cinco modos de debatir y recurre a las siguientes metáforas: Polémica, metáfora bélica (debatir es luchar); trato, metáfora mercantil (debatir es comerciar); enfrentamiento, metáfora lúdico-deportiva (debatir es jugar); indagación, metáfora exploradora (debatir es viajar); coloquio, metáfora constructora (debatir es construir). Cfr. CATTANI, op. cit., 74 y ss. En mi opinión, frente a lo sostenido por CATTANI y aunque aquí no lo voy a desarrollar, el trato (la negociación) no puede oponerse a los otros modos de debatir por la sencilla razón de que el debate que tiene lugar en una negociación puede adoptar cualquiera de las otras formas de diálogo argumentativo. Como se verá, las caracterizaciones y las asignaciones de nombres de los modos de debatir que voy a hacer tampoco coincidirán con las propuestas por CATTANI.

6 Naturalmente hay muchísimas clasificaciones de diferentes tipos de diálogo argumentativo que usan diferentes tipos de variables. Por ejemplo, WALTON a partir de las variables «situación inicial», «finalidad»y «beneficios» construye los siguientes diez tipos básicos de diálogo: Persuasión, debate, indagación, negociación, diálogo en comisión (planning committee), diálogo pedagógico, deliberación, disputa (quarrel), entrevista y consulta de expertos. Cfr. D. N. WALTON, Arguments from Ignorance, The Pennsylvania State University, 1996, 190. M. DASCAL, por su parte, distingue tres tipos ideales de «diálogos polémicos». Así, recurriendo a las variables «objeto», «causa», «pretensión de los contendientes», «terminación del diálogo», «táctica preferente», «campo de aplicación» y «tipo de racionalidad», distingue entre discusiones, disputas y controversias. Sobre esta clasificación de DASCAL, vid. M. AtienZA, Curso ..., op. cit., 387 y ss.

7 Cuando en un debate se habla de conflicto y de cooperación no sólo debe tenerse en cuenta el hecho de que los interlocutores tengan objetivos incompatibles (conflicto) o complementarios (cooperación), sino también la actitud abierta y/o cerrada con la que los sujetos se aproximan al problema (la cuestión) que es objeto de debate. 
ración, pues tal término probablemente no exista. Trata, más bien, de dar cuenta de situaciones ambiguas, es decir, de relaciones en las que la combinación de elementos de cooperación y de conflicto no permite caracterizar la relación en su conjunto como cooperativa o como conflictiva. La ambigüedad de estas situaciones intermedias -a caballo entre el conflicto y la cooperación- se traduce en incertidumbre de cada participante respecto de las intenciones y actitudes que pueda mostrar su interlocutor.

\subsection{Debatir es combatir}

Los interlocutores que combaten se acometen, pelean, batallan, contienden, luchan, embisten, etc. Es así porque la finalidad de su interlocución es la destrucción del otro. Para cada interlocutor, el otro es un enemigo y su destrucción es sinónimo de la propia victoria. Si el interlocutor «sale vivo» del debate, la victoria no ha sido plena. La victoria se consigue cuando el otro queda desorientado, balbuciente, humillado, descalificado, lloroso, desarmado, es decir, derrotado. Ejemplos de este tipo de enfrentamientos son los debates erísticos, tales como los enfrentamientos políticos, las peleas de pareja, los diálogos de sordos, etc. Lo característico de este tipo de debate es que no es posible separar el objeto de discusión de los sujetos de la discusión. Y no es posible porque para cada interlocutor el problema central, en realidad, es el otro interlocutor. El objeto de discusión es en muchas ocasiones meramente accesorio y circunstancial. El sentido de la intervención es la descalificación. Es evidente, por ejemplo, que el sentido de «iVáyase Sr. González!» pronunciado por Aznar combinaba con cualquier tema en discusión; valía lo mismo tanto si el debate versaba sobre el paro, sobre Europa o sobre las pensiones. El problema de Aznar era González, no el paro, Europa o las pensiones.

Naturalmente, las reglas formales e informales que rigen este tipo de debates tienen características propias. Por ejemplo, en este contexto discursivo nadie podría alegar que se está incumpliendo algo por el hecho de que uno de los interlocutores esté argumentando ad hominem; y no se podría alegar por la sencilla razón de que este tipo de debate va precisamente de eso. Imaginemos una pelea de pareja en la que uno de los miembros le dice al otro: «Eres un inútil. Todo lo haces mal. El mayor error de mi vida ha sido casarme contigo». El detonante de la discusión puede haber sido cualquier «objeto» de conflicto porque en realidad es accesorio en relación con la intervención. El cónyuge vilipendiado ha invertido los ahorros familiares en la estafa de las preferentes, o ha sido incapaz de arreglar un enchufe o es un vago que no hace nada en relación con las tareas de la casa. La finalidad de la intervención («eres un inútil...») es herir, dañar, castigar o, incluso, por qué no, hacer justicia («he puesto las cosas claras y le he dicho todo lo que se merece»). Hay un objeto de conflicto pero la atención se centra sobre todo en los sujetos del conflicto.

Podría dudarse del carácter argumentativo de estos debates e intercambios al considerar que un puro intercambio de descalificaciones no tiene contenido argumentativo. Naturalmente no toda descalificación verbal contiene un argumento, pero muchas de ellas sí. No entender esto supone no entender gran parte del lenguaje del conflicto, del diálogo que acompaña al conflicto. Imaginemos que un contendiente le dice al otro: «Eres un sinvergüenza, un cerdo traidor que ha filtrado información». Es eviden- 
te que esta intervención tiene una clara intención de dañar, avergonzar, castigar, etc. pero tiene también un claro contenido argumentativo. Desde la dimensión formal de la argumentación, el argumento podría presentarse así: «Quien filtra información es un traidor»; «has filtrado información»; luego «eres un traidor».

Esta misma operación cabría hacerla en el caso de la esposa que «enfatizaba» la inutilidad del marido: «Eres un inútil porque te has dejado engañar», «... porque no sabes ni arreglar un enchufe», o «... porque nunca haces nada». Es decir, en cualquiera de estos tres casos hay una razón para el juicio de inutilidad, pero el énfasis no está puesto en eso, en el objeto de conflicto; sino en la actitud de combate del que habla, en la intención de derrotar al interlocutor. Es, en este sentido, un conflicto más actoral que objetual (temático). Pasemos ya al siguiente nivel de debate que va a suponer una transición de conflicto esencialmente actoral a conflicto esencialmente objetual.

\subsection{Debatir es competir}

Los interlocutores que compiten pretenden ganar y ello supone aceptar que la contraparte tiene que perder; el juego es, por tanto, ganar-perder. Los objetivos de los interlocutores son estrictamente incompatibles entre sí, por lo que seguimos en el ámbito propio del conflicto. En este aspecto no hay diferencia entre este modo de debatir y el anterior. ¿Dónde radica, pues, la diferencia entre combatir y competir como modos de debate? Esencialmente en dos puntos: Primero, quienes compiten se reconocen una legitimidad que no se reconocen quienes combaten. Este reconocimiento de legitimidad se traduce en que el objetivo de los actores es defender una tesis y/o rebatir una tesis opuesta, pero no destruir o descalificar al adversario. En este sentido y a diferencia de lo que ocurría en el debate combativo, el debate competitivo es temático, tiene tintes mucho más objetuales que actorales. Por ilustrarlo en lenguaje llano, aquí podrá alegarse «eso que dices es una tontería porque...» pero ya no valdrá decir al oponente «eres un imbécil porque...». Ahora hay un objeto de debate distinto y separado de los interlocutores. Una buena manera de mostrar este cambio discursivo es atender al papel de traductor del lenguaje del conflicto que desde siempre se ha atribuido al rol del abogado en relación con su cliente. El cliente, que es un actor del conflicto, tiende a personalizar el problema mientras que el abogado, que es un profesional del conflicto, debe tratar de despersonalizarlo, de objetivarlo. Segundo, combatir y competir como formas de debate se diferencian también por el papel que juegan las reglas. En general, «debatir es competir» es una actividad mucho más reglada que «debatir es combatir». Si bien se considera, una guerra sin reglas es concebible; una competición, no. En la propia definición de competición está la idea de regla; y conectada con ella la de competir respetando las reglas del juego limpio. Todos los ámbitos competitivos ordinarios están reglados: los mercados, los juegos, los deportes, los juicios, etc. En este tipo de debates es característica la denuncia de falacias en el sentido de trampas discursivas, de violación de las reglas del discurso, etc. Las reglas serán formales o informales dependiendo del grado de institucionalización y del contexto en que tenga lugar este tipo de debate, pero es consustancial al mismo la existencia de reglas. Naturalmente no es lo mismo una vista oral de un juicio, una mesa redonda sobre la despenalización del aborto o una discusión de bar sobre si Messi o Cristiano, pero en todos estos contextos 
de debate hay reglas y los interlocutores están atentos al grado de cumplimiento de las mismas.

En «debatir es competir», la situación inicial es la dos sujetos que mantienen posiciones enfrentadas sobre una cuestión que resulta controvertida; es decir, los interlocutores mantienen posiciones incompatibles (hay antagonismo) pero se reconocen plena legitimidad. Por eso, en términos generales, las argumentaciones ad hominem se consideran falaces, porque no está en cuestión la legitimidad del interlocutor. La finalidad que persiguen los interlocutores es ganar. La forma más clara y contundente de ganar un debate de este tipo es derrotar al adversario: que el contrincante «arroje la toalla», que conceda la victoria, porque se ha quedado sin razones. Nótese que conceder la victoria no es estrictamente equivalente a dar la razón; en este modo de debatir, lo sujetos tienen una actitud cerrada respecto de la cuestión controvertida, no están dispuestos a cambiar de opinión. Este resultado óptimo es ciertamente infrecuente; tanto es así que bien puede decirse que la finalidad de los participantes no es ni mucho menos convencer al contrincante, sino definir de manera clara los puntos de acuerdo y desacuerdo. Fijar con precisión qué les une y qué les separa, porque una forma típica de proceder es delegar el juicio: que juzgue un tercero. Este rol del tercero puede estar más o menos institucionalizado, pero es bien claro. Retomando los tres ejemplos antes mencionados, el tercero puede ser el juez que preside la vista oral, el público que asiste a la mesa redonda sobre el aborto o los compañeros de la tertulia de café que son testigos de la controversia sobre si Messi o Cristiano.

\subsection{Debatir es explorar y/o diagnosticar}

En el ámbito de la medicina, diagnosticar es recoger y analizar datos para llegar a determinar el carácter de una enfermedad. «Debatir es diagnosticar» evoca la imagen de una sesión clínica. Un conjunto de médicos reunidos en torno a una historia clínica (es decir, en torno al conjunto de los datos recabados en los diferentes exámenes realizados a un paciente durante la exploración) con la finalidad de llegar a determinar qué enfermedad padece y qué tratamiento hay que aplicarle. Todos los participantes en la sesión clínica persiguen lo mismo: realizar un diagnóstico correcto y determinar el tratamiento adecuado. Esta profunda unidad de fines impregna toda esta forma de debatir. En efecto, es posible que en el desarrollo de una sesión clínica los interlocutores lleguen a formular hipótesis incompatibles entre sí, pero ello no altera la naturaleza de este tipo de debate; solo un observador muy superficial podría llegar a pensar que ese mero hecho hace que «debatir es diagnosticar» se transforme en «debatir es competir». La diferencia entre una forma y otra de debate no radica en eso, en que pueda haber contraste de opiniones. Estriba en que el punto de partida en «debatir es diagnosticar» no es un enfrentamiento en torno a una cuestión controvertida (como en «debatir es competir»), sino en torno a una cuestión que todos los interlocutores consideran difícil. En efecto, en «debatir es competir» (en las controversias) se trata de un choque dialéctico entre sujetos que tienen resuelta la cuestión controvertida: Para cada uno de los contendientes individualmente considerados la cuestión a debatir es fácil; su actitud en relación con el problema de fondo es cerrada, pues no están dispuestos a cambiar de opinión; y ocurre que consideran que el interlocutor está simultáneamente 
equivocado y cerrado al cambio. Nada de esto ocurre en «debatir es diagnosticar»: La dificultad de la cuestión, la conciencia de la dificultad de la cuestión, es lo que dota de sentido cooperativo a la participación en esta forma de debate. En torno a los síntomas de un simple resfriado no tiene propósito organizar una sesión clínica. Nótese que la finalidad de una sesión clínica no es tanto ponerse de acuerdo en torno al diagnóstico y el tratamiento; sino poner en común los conocimientos de cada uno de los participantes para que, tras el debate, todos los que han participado en él entiendan mejor el problema y vean con más claridad su solución; es decir, estén en condiciones de hacer un diagnóstico mejor ${ }^{8}$.

Ejemplos de debates de este tipo se dan en la investigación científica, en los seminarios universitarios, en las comisiones de asesoramiento, en los tribunales colegiados, etc. La situación inicial entre los participantes es de cooperación: Les une, por un lado, el hecho de compartir un problema que todos ellos consideran difícil y, por otro, la conciencia, también compartida, de que debatir el problema aumenta de manera sobresaliente las probabilidades de resolverlo satisfactoriamente o, al menos, de verlo con mayor claridad. Es decir, todos los participantes piensan que, con independencia de que se pongan de acuerdo o no respecto de la solución del problema difícil, el debate es, en sí mismo, productivo; es, en sí mismo, un bien. Coloca a todos los participantes en mejores condiciones de abordar el problema y de resolverlo. Coherentemente con ello, los interlocutores se reconocen plena legitimidad. Antes dije que «debatir es diagnosticar» exige un problema difícil (no tiene sentido una sesión clínica en torno a un simple catarro); pues bien, «pide» también interlocutores competentes: gente con capacidad para arrojar luz sobre el problema difícil. Por tanto, el reconocimiento de legitimidad entre los participantes en este tipo de debate pende sobre dos cosas: a) Competencia para aportar algo a la solución del problema; no se entabla este tipo de debate con alguien a quien se considera o bien un ignorante en la materia o bien un «zoquete». Y b) actitud cooperativa suficiente; en este sentido, la «gorronería», la reserva mental, la hostilidad, los complejos de superioridad, o de inferioridad, la pretensión de autoridad, la arrogancia, la vanidad, etc., son obstáculos para una actuación legítima en esta forma de debate.

8 En este punto conviene llamar la atención respecto del llamado «escepticismo» en el ámbito de la razón práctica, en general, y de la interpretación del derecho, en particular. El ejemplo de la sesión clínica es plausible y aceptable para todo el mundo porque se trata de un problema teórico (de un problema de conocimiento sobre la enfermedad, de incertidumbre respecto de la enfermedad). En este ámbito, todo el mundo acepta que puede haber casos difíciles que generan incertidumbre, pero nadie piensa que haya casos de indeterminación. Por eso, en el ámbito teórico todo el mundo admite que tiene sentido «debatir es diagnosticar». Sin embargo, todos los escépticos en el ámbito de la razón práctica tienden a pensar que, en realidad, en este ámbito no hay casos de incertidumbre, sino más bien casos de indeterminación. En el ámbito de la razón práctica, los escépticos piensan que si hay convención (acuerdo), entonces no hay caso difícil; y si no hay convención entonces tampoco hay caso difícil, lo único que hay es caso controvertido. O, dicho en otros términos, para un escéptico la única fuente de dificultad provendrá de la controversia. Si el problema/ caso está convencionalmente resuelto entonces el problema/caso no es difícil; y si el problema/caso no está convencionalmente resuelto entonces no hay una única solución para ese caso; y, por tanto, no tiene sentido debatirla como si la hubiera. Los escépticos en el ámbito de la razón práctica vendrían a sostener que más allá de la convención solo hay controversia («debatir es competir») e indeterminación («no hay una única respuesta correcta»); los no escépticos admiten la deliberación («debatir es diagnosticar») y la incertidumbre («puede haber una respuesta correcta, aunque no la conozcamos»). Sobre el escepticismo y la distinción entre incertidumbre e indeterminación, vid. R. Dworkin, Justice for Hedgehogs, Cambridge (Mass.), Harvard University Press, 2011, 88 y ss. 
Si se tiene claro lo anterior, es fácil de entender el papel específico que las reglas juegan en el ámbito de «debatir es diagnosticar». Al no tratarse de un debate competitivo, la finalidad de las reglas no es tanto garantizar los «derechos» de los participantes en el debate (pues no se oponen unos a otros), cuanto preservar el sentido cooperativo y productivo del mismo. Por ejemplo, si en un debate de esta naturaleza dos interlocutores se encastillan (ya sea por vanidad, cabezonería o, incluso, por creencia firme en que tienen razón), no tiene sentido empezar a pensar en términos de igualdad de derechos (de a tantas réplicas corresponden tantas dúplicas y cosas por el estilo); lo que procede, más bien, es cortar de raíz los intercambios improductivos y reordenar el debate para que vuelva a cumplir la función que se espera de él. Naturalmente, puede debatirse «fuerte», no hay ningún inconveniente en que la discusión sea intensa. Es más, puede pensarse que si no se es duro con el problema (si, por ejemplo, no se aguantan suficientemente las posturas encontradas), el debate pierde su sentido productivo, su sentido de «exploración». La tensión intelectual es fundamental para que el debate resulte fructífero; en consecuencia, las reglas no pueden (no deben) oponerse a la referida tensión intelectual, sino más bien favorecerla. Si bien se considera, las reglas que regulan «debatir es diagnosticar» son siempre un compromiso entre dos principios: el principio de productividad (el debate debe ser productivo, esclarecedor, provechoso, fructífero, etc.) y el principio de cooperación (debe ser un juego de ganar-ganar, no de ganar-perder).

Para acabar de perfilar «debatir es diagnosticar» tratemos de poner algunos ejemplos de conductas aquí prohibidas que, sin embargo, se consideran perfectamente permitidas, por ejemplo, en «debatir es competir». En un debate competitivo se considera lícito deformar «algo» (simplificar, caricaturizar, etc.) las tesis del contrincante con el fin de allanar el camino para la crítica. Naturalmente, puede ocurrir que alguien «se pase» en la deformación y que, en consecuencia, no consiga los efectos buscados. Habrá errado en su estrategia al realizar este lance de juego, pero no habrá incumplido ninguna regla del juego. La misma conducta — deformar para criticar- es estrictamente ilícita en «debatir es diagnosticar». La razón no es tanto salvaguardar los derechos del sujeto pasivo de la deformación, cuanto preservar el bien colectivo del debate y su carácter productivo; no se trata de ganar (quién gana) sino de aclarar un problema difícil. En definitiva, algo que resulta válido para un juego estratégico del tipo ganar-perder está estrictamente prohibido para un juego comunicativo del tipo ganar-ganar ${ }^{9}$.

Otro ejemplo de conducta prohibida es la descalificación directa de tesis relativas al problema objeto de discusión sostenidas por algún interlocutor. Naturalmente no se trata de tolerar el puro ruido deliberativo o el mero error, sino más bien de que la dinámica del debate favorezca la «creatividad» en la búsqueda de las respuestas; y para

9 En este ámbito, en «debatir es diagnosticar», el debate no es un mero marco para ganar; en consecuencia, la práctica del debate requiere más que una correcta distribución de derechos y deberes entre los interlocutores, el desarrollo de ciertas virtudes discursivas por parte de los participantes en el mismo. A propósito de la noción de virtud, escribe MACINTYRE: «[U]na virtud es una cualidad humana adquirida, cuya posesión y ejercicio tiende a hacernos capaces de lograr aquellos bienes que son internos a las prácticas y cuya carencia nos impide efectivamente el lograr cualquiera de tales bienes [...] los bienes externos son típicamente objeto de una competencia en la que debe haber perdedores y ganadores. Los bienes internos son el resultado de competir en excelencia, pero es típico de ellos que su logro es un bien para toda la comunidad [en nuestro caso, para todos los participantes en el debate]», en A. MACInTYre, Tras la virtud (trad. A. VALCÁRCEL), Barcelona, 1987, 237. 
ello no hay que impedir que los interlocutores asuman ciertos «riesgos» en la formulación de propuestas. Así ocurre, por ejemplo, en las llamadas «tormentas de ideas», que son un caso paradigmático de forma cooperativa de debatir. Pero, más en general, si los interlocutores se reconocen plena legitimidad (no se olvide que aquí entraña reconocerse capacidad intelectual y actitud cooperativa, no se debate de este modo con incompetentes ni con zoquetes) frases del tipo de «eso que dices es una chorrada» están estrictamente fuera de lugar.

Si prescindimos de los elementos circunstanciales que limitan los debates reales (como, por ejemplo, el tiempo), «debatir es diagnosticar» se termina cuando se extinguen las condiciones de la cooperación; es decir, cuando todos los interlocutores emiten un «ya tengo un diagnóstico», un «ya tengo clara la solución del problema difícil». Lo que de entrada (la situación inicial) era un problema difícil para todos, en la salida (el resultado típico) es un «todos lo tenemos claro». Nótese que del hecho de que todos los interlocutores tengan clara la solución del problema no se sigue que todos ellos participen de la misma solución. Se sigue solo que para todos ellos (para cada uno de ellos) el problema deja de ser difícil y, en consecuencia, pierde sentido la cooperación. Naturalmente puede ocurrir que se produzca una concurrencia de «conciencias esclarecidas» por el debate; es decir, que todos alcancen el mismo diagnóstico. En tal caso, los participantes podrán felicitarse porque el debate habrá resultado doblemente productivo, pues se habrá generado, por un lado, el esclarecimiento de cada una de las conciencias de los participantes a propósito del problema difícil y, por otro, un consenso por concurrencia en relación con el mismo. Ahora bien, el sentido de este tipo de debate es contribuir a esclarecer las conciencias de los participantes en torno a un problema difícil, no resolver un problema de coordinación entre ellos. En consecuencia, una vez esclarecidas las conciencias, este tipo de debate se extingue. Si la interlocución argumentativa entre los participantes continúa (es decir, si el debate continúa), entonces necesariamente se abandona la forma «debatir es diagnosticar» y se transita hacia otra forma de debate. Básicamente, caben dos posibilidades. La primera es transitar a «debatir es competir». El final de la cooperación entre los interlocutores da comienzo a una competencia entre ellos para conseguir ganar. Nótese que lo que era un problema difícil en la entrada de «debatir es diagnosticar», se convierte en una «cuestión controvertida» en la salida, es decir, cuando todos «lo tienen claro» pero no están de acuerdo. La otra posibilidad, en términos de debate, es transitar al último tipo ideal que voy a desarrollar, es decir, transitar a «debatir es construir».

\subsection{Debatir es construir}

«Construir» es fabricar, edificar, crear algo dotado de unidad, separado y distinto de los constructores. Quienes construyen conjuntamente algo resuelven problemas de dos tipos. Por un lado, problemas de conocimiento y, por otro, problemas de coordinación de conductas (construir implica hacer, no basta con saber). Pues bien, transitar de «debatir es diagnosticar» a «debatir es construir» supone dar un paso más en el nivel de cooperación entre los sujetos que debaten. ¿En qué consiste este paso? Las reglas que rigen el proceso de este tipo de debate son prácticamente las mismas que las del anterior. Se trata también de un debate cooperativo que persigue esclarecer 
las conciencias de los participantes, su conocimiento reflexivo. Aquí, además de los principios de productividad (el debate debe ser productivo, provechoso, fructífero, esclarecedor, etc.) y de cooperación (el debate debe ser un juego de ganar-ganar, no de ganar-perder), rige también el principio de consenso. ¿Qué entraña la incorporación de este nuevo principio? Más o menos lo siguiente: La legitimidad que se reconocen recíprocamente los interlocutores es de tal magnitud que todos ellos aceptan que no alcanzar el consenso en torno a una respuesta correcta significa para todos ellos que no han resuelto el problema. En tanto no hay consenso, avenencia, no hay solución del problema. Por ello, respecto de este tipo de debate suele decirse que el consenso es constitutivo de la solución del problema. La solución es, y solo puede ser, una «obra» de todos los interlocutores. Naturalmente si uno analiza este tipo de debate en términos de poder, el resultado que obtiene es realmente muy poco atractivo. En efecto, supone reconocer un «derecho de veto» a cada participante, lo que, al final, puede acabar resultando totalmente despótico e inoperante. Por ello, y porque en términos sociales los elementos de poder son ineliminables, suele decirse que no es recomendable seguir este esquema de debate en el diseño de instituciones sociales. Ahora bien, de ahí no se sigue que no haya contextos en los que esta forma de debate tenga pleno sentido. En efecto, antes dije a propósito del otro tipo de debate cooperativo («debatir es diagnosticar») que entender sus reglas en términos de derechos y deberes de los participantes era un error porque en el contexto de ese debate los sujetos no se oponen los unos a los otros; entre ellos hay una unidad de fines que hace innecesaria la apelación a derechos y deberes. Lo mismo ocurre aquí con la cuestión del poder. No tiene sentido decir que cada interlocutor reconoce un poder (derecho) de veto a los otros interlocutores. La situación es otra, los interlocutores mantienen entre sí tal grado de «necesidad recíproca» (se «necesitan» tanto), que para cada uno de ellos el hecho de que el otro no acepte la solución propuesta constituye una razón para creer que, en realidad, la propuesta no constituye realmente una solución. No olvidemos que el reconocimiento de la legitimidad depende del reconocimiento, por un lado, de competencia (capacidad) para contribuir a la solución del problema y, por otro, de actitud cooperativa. Pues bien, el reconocimiento máximo de legitimidad entre interlocutores lleva a reconocerse recíprocamente no un derecho de veto (pues en este tipo de debate no hay espacio para ese derecho), sino que si no hay consenso, no hay solución del problema. La metáfora constructiva expresa bien que la solución al problema difícil no es una cuestión de mero esclarecimiento de las conciencias individuales, sino de crear algo distinto y separado de las mismas. Aunque este tipo de debate se presta mucho a la idealización, aquí interesa sobre todo situarlo en contextos reales y cotidianos. Y para ello es fundamental darse cuenta de que cualquier posibilidad de alcanzar tan alto grado de cooperación discursiva pende más sobre la identidad (la relación) de los sujetos que sobre la naturaleza del problema a resolver. Explica más la peculiar necesidad (o, incluso, afecto) entre los interlocutores que la dificultad del problema que se trata de resolver. Es, en este sentido, una cooperación más actoral que objetual. Pongamos un ejemplo bien real y cotidiano de esta forma de debatir. Imaginemos una pareja bien avenida que tiene un hijo en edad de ser escolarizado. Los padres tienen diversas opciones y ambos piensan que, en los tiempos que corren, es difícil saber qué es lo mejor para su hijo. A pesar de que no se trata de una cuestión controvertida (porque ambos se mantienen abiertos) ocurre que, en principio, tienen 
preferencias diferentes. Los dos se reconocen mutuamente plena capacidad para evaluar la situación y plena disposición a cooperar para determinar qué es lo mejor para su hijo. Ninguno de los dos piensa que la cuestión pueda abordarse en términos de un intercambio y, por tanto, desde el principio excluyen la posibilidad de un acuerdo del siguiente tipo: «Dado que no opinamos igual, los dos cedemos en algo: tú eliges el colegio y yo las actividades extraescolares». ¿Qué alternativas tienen? La mejor alternativa es entablar un diálogo cooperativo orientado no solo a esclarecer la conciencia de cada uno de ellos respecto de qué es lo mejor para su hijo, sino también a fraguar un consenso. Para que ello sea posible no se trata — como ya se ha dicho- de que ambos se otorguen recíprocamente un derecho de veto. Se trata, más bien, de que cada uno reconozca en su interlocutor un sujeto con tanta capacidad y actitud como las propias (tanta legitimidad como a uno mismo) de forma que cada uno pueda pensar que si el otro no ve clara la solución del problema es que, en realidad, la solución del problema no está clara. En estas condiciones, todo lo que no sea genuino consenso entre los participantes es pura pérdida para todos ellos.

Esta misma idea de pérdida para todos es la que está referida tras la noción, por ejemplo, de «consenso constitucional». En un proceso constituyente, siempre que una «facción política» abandona el «consenso constitucional» puede hablarse de fracaso constitucional. De la noción de fracaso constitucional no se sigue un deber de las otras facciones políticas de hacer concesiones para que la que se ha retirado regrese al consenso (eso sería reconocerle un derecho de veto), sino simplemente la idea de que o bien la constitución es obra de todos, o bien todos pierden en algún sentido.

\section{LOS CUATRO TIPOS IDEALES DE DEBATE EN RESUMEN Y CON SUS NOMBRES}

A continuación presento un cuadro que trata de resumir todo lo anterior. Sin embargo, el cuadro incorpora dos novedades respecto de lo ya expuesto. La primera es que el cuadro está dotado de una simetría de la que ha carecido la exposición anterior; y ello tiene la ventaja de que permite (facilita) la comparación entre los diferentes modos de debatir. La segunda novedad es que el cuadro asigna un nombre a cada modo de debatir. La cuestión de los nombres es controvertida pero no fundamental; por ello, sigo evitando su problematización.

\section{CUATRO MODOS DE DEBATIR}

\begin{tabular}{|l|l|}
\hline 1. Debatir es combatir. & $\begin{array}{l}\text { Ejemplos: } \\
\text { DISPUTA }\end{array}$ \\
$\quad$ Debates erísticos: enfrentamiento político, pelea de pareja, \\
Relación entre los interlocutores: \\
- De conflicto (ganar-perder). \\
$-\begin{array}{l}\text { Debate actoral (el problema es el interlocutor, los temas son } \\
\text { accesorios). } \\
\text { - Hostilidad. }\end{array}$ \\
\hline
\end{tabular}




\begin{tabular}{|c|c|}
\hline $\begin{array}{l}\text { 1. Debatir es combatir. } \\
\text { DISPUTA }\end{array}$ & $\begin{array}{l}\text { Finalidad del Debate: } \\
\text { — Determinar qué interlocutor se impone al otro. } \\
\text { Situación inicial: } \\
\text { — Incertidumbre en relación con quién se va a imponer. } \\
\text { — Certeza respecto de la actitud del interlocutor: rivalidad. } \\
\text { Tipo de racionalidad: } \\
\text { — Estratégica (orientada al propio éxito). } \\
\text { Posibles resultados: } \\
\text { - Un actor gana y otro pierde (uno se impone al otro). } \\
\text { - Ningún actor gana (ninguno se impone). } \\
\text { Reglas: } \\
\text { - Procedimentales y neutrales que garanticen el principio de } \\
\text { igualdad de derechos entre los interlocutores. }\end{array}$ \\
\hline $\begin{array}{l}\text { 2. Debatir es competir. } \\
\text { CONTROVERSIA }\end{array}$ & $\begin{array}{l}\text { Ejemplos: } \\
\text { - Debate legislativo, mesa redonda, ponencia y contra-ponencia, } \\
\text { acusación y defensa. } \\
\text { Relación entre los interlocutores: } \\
\text { - De conflicto (ganar-perder). } \\
\text { - Debate temático (hay una cuestión controvertida; el problema } \\
\text { está separado de las personas). } \\
\text { - Cabe tanto la hostilidad como la cordialidad. } \\
\text { Finalidad: } \\
\text { - Determinar qué opinión prevalece frente a otras a propósito de } \\
\text { una cuestión controvertida. } \\
\text { Situación inicial: } \\
\text { - Incertidumbre respecto de qué opinión va a prevalecer. } \\
\text { - Certeza respecto de la actitud competitiva (cerrada) del inter- } \\
\text { locutor. } \\
\text { Tipo de racionalidad: } \\
\text { - Estratégica (orientada al propio éxito). } \\
\text { Posibles resultados: } \\
\text { - Una opinión prevalece sobre las demás. } \\
\text { - Exposición de las respectivas opiniones y delegación del juicio } \\
\text { en un tercero (el público, un juez, etc.). } \\
\text { Reglas: } \\
\text { - Procedimentales y neutrales que garanticen el principio de } \\
\text { igualdad de derechos entre los interlocutores. } \\
\text { - Sustantivas que aseguren el carácter temático del debate, } \\
\text { interlocutores no evadan la cuestión (principio de contro- } \\
\text { versia). }\end{array}$ \\
\hline
\end{tabular}




\begin{tabular}{|c|c|}
\hline $\begin{array}{l}\text { 3. Debatir } \\
\text { es diagnosticar } \\
\text { DIÁLOGO RACIO- } \\
\text { NAL, DELIBERACIÓN }\end{array}$ & $\begin{array}{l}\text { Ejemplos: } \\
\text { - Sesión clínica, investigación científica, deliberación de un tri- } \\
\text { bunal judicial o de un tribunal de oposiciones, comisión técni- } \\
\text { ca, etcétera. } \\
\text { Relación entre los interlocutores: } \\
\text { - De cooperación (ganar-ganar). } \\
\text { - Debate temático (sin problema difícil no hay diálogo racional, } \\
\text { deliberación) } \\
\text { - Cordialidad; la hostilidad está fuera de lugar. } \\
\text { Situación inicial: } \\
\text { - Incertidumbre sobre si se va a resolver el problema difícil. } \\
\text { - Certeza respecto del valor del debate mismo. } \\
\text { - Certeza respecto de la capacidad de los interlocutores y de su } \\
\text { actitud cooperativa (abierta). } \\
\text { Finalidad: } \\
\text { - Resolver un problema difícil o, al menos, arrojar luz sobre el } \\
\text { mismo. } \\
\text { Racionalidad: } \\
\text { - Comunicativa (orientada al entendimiento). } \\
\text { Posible resultado: } \\
\text { - Todos alcanzan una solución del problema («ya lo tengo cla- } \\
\text { ro», ganar-ganar). } \\
\text { - La concurrencia en la misma solución es contingente, no de- } \\
\text { finitoria. } \\
\text { - Cuando todos lo tienen claro, se extinguen las condiciones de } \\
\text { posibilidad de este tipo de debate. } \\
\text { Reglas: } \\
\text { - Todas las reglas, tanto las procedimentales como las sustantivas, } \\
\text { responden a los principios de productividad (el debate debe } \\
\text { ser fructífero) y el principio de cooperación (todos ganan). Es } \\
\text { más una cuestión de virtudes que de derechos y deberes. }\end{array}$ \\
\hline 4. Debatir es construir & $\begin{array}{l}\text { Ejemplos: } \\
\text { - Debates constituyentes, equipos de trabajo, diseño de planes } \\
\text { de vida compartidos, etcétera. } \\
\text { Relación entre los interlocutores: } \\
\text { - De cooperación (ganar-ganar). } \\
\text { - Debate actoral (sin la aveniencia del otro, el problema no se } \\
\text { resuelve) } \\
\text { - Cordialidad; la hostilidad está fuera de lugar. De necesidad re- } \\
\text { cíproca. } \\
\text { Situación inicial: } \\
\text { - Incertidumbre sobre si el debate va generar el consenso o no. } \\
\text { - Certeza respecto de la competencia de los interlocutores y su } \\
\text { actitud cooperativa (abierta). }\end{array}$ \\
\hline
\end{tabular}




\begin{tabular}{|c|c|}
\hline $\begin{array}{l}\text { 4. Debatir es construir } \\
\text { CONSENSO }\end{array}$ & $\begin{array}{l}\text { Finalidad: } \\
\text { — Alcanzar un consenso. } \\
\text { Racionalidad: } \\
\text { — Comunicativa (orientada al entendimiento). } \\
\text { Posibles resultados: } \\
\text { — Se alcanza el consenso: Todos llegan a la solución. Nadie cede } \\
\text { nada. Todos ganan. } \\
\text { — No se alcanza el consenso: Nadie alcanza una solución. Todos } \\
\text { pierden. } \\
\text { - Este tipo de debate se extingue cuando decae el reconocimien- } \\
\text { to recíproco del grado de legitimidad exigido para el mismo. } \\
\text { Reglas: } \\
\text { - Todas las reglas, tanto las procedimentales como las sustan- } \\
\text { tivas, responden a los principios de productividad (el debate } \\
\text { debe ser fructífero), el principio de cooperación (todos ganan) } \\
\text { y el principio de consenso (el consenso es constitutivo de la } \\
\text { solución). Es más una cuestión de virtudes que de derechos y } \\
\text { deberes. }\end{array}$ \\
\hline
\end{tabular}

\section{TRANSICIONES E INSTITUCIONALIZACIÓN DE LOS DEBATES}

Todo lo anterior supone una reducción de complejidad y muchas cuestiones relevantes se han quedado fuera de nuestro discurso. Lo que hemos hecho, en realidad, es tratar los diferentes modos de debatir bajo el prisma de la relación social; y, a partir de ahí, hemos tomado la variable conflicto/cooperación como la clave esencial para componer nuestra caracterización. Así, nos han salido dos formas de debatir conflictivas (una actoral, la disputa, y otra temática, la controversia) y dos formas cooperativas (una temática, el diálogo racional, y otra actoral, el consenso). La utilidad de estos «tipos ideales» radica en que nos permiten reconocer e interpretar las distintas situaciones sociales de debate. Ahora bien, la realidad es compleja y continua, y puede ocurrir que haya situaciones concretas de debate que no se dejen encasillar en uno solo de los tipos propuestos. Los debates reales son fluidos y se producen, consciente o inconscientemente, transiciones de un tipo de debate a otro. Es más, ocurre con relativa frecuencia que las transiciones sean asimétricas, es decir, que no todos los interlocutores transiten simultáneamente y en la misma dirección. Por ejemplo, en un diálogo racional, un interlocutor evoluciona hacia una controversia mientras que el otro sigue guiándose por las reglas del diálogo cooperativo; o en una controversia, uno evoluciona hacia una disputa y otro hacia un diálogo racional. Pues bien, las transiciones unilaterales o desequilibradas constituyen una de las principales fuentes de falacias en un debate. Recuérdese, como ya vimos, que lo que no es falaz en un tipo de debate perfectamente puede serlo en otro ${ }^{10}$.

10 Cfr. D. N. Walton y E. C. W. KrabBe, Commitment in Dialogue. Basic Concepts of Interpersonal Reasoning, Albany, State University of New York Press, 1995, 100 y ss. Sobre esta cuestión y, más en general, sobre las falacias pragmáticas vid. M. AtIENZA, Curso de argumentación jurídica, op. cit., 404 y ss. 
Los debates reales, los que tienen lugar en nuestra vida social, están más o menos institucionalizados, pero siempre están regulados por convenciones. Por ejemplo, dentro del tipo de las controversias, el debate de bar sobre si Messi o Cristiano está mucho menos institucionalizado que la mesa redonda sobre la despenalización del aborto. Eso es evidente. La institucionalización de un debate tiene la ventaja de la claridad: todos los interlocutores saben a qué juego están jugando. No quiero detenerme mucho en las formas institucionales de los distintos tipos de debate porque creo que, más o menos, todos las tenemos presentes. Sí quiero, sin embargo, llamar la atención sobre un punto especialmente importante: las dos formas de debate conflictivo «piden» que se institucionalice la presencia de terceros; mientras que la de las dos formas de debate cooperativo, no. Veámoslo brevemente.

Imaginemos un debate entre dos candidatos a la presidencia de un país. La desconfianza entre los dos contendientes hace que deban tomarse medidas que garanticen sus respectivos «derechos». Interponer entre los contendientes la presencia de un tercero neutral que vigile el cumplimiento de las reglas es una medida institucional tan básica que parece casi de «derecho natural». Alguien podría pensar que la presencia institucional de un tercero desvirtúa la metáfora bélica que hemos utilizado para caracterizar las «disputas», pero ello no es así. Un «duelo» no es otra cosa que la institucionalización de una pelea a muerte (o a primera sangre). El conflicto, la incompatibilidad de los objetivos de los interlocutores (o de los duelistas), es el que «pide» la institucionalización de un tercero neutral que vele por los derechos de los contendientes. Ahora bien, el sentido de este tipo de debates, de las disputas, nunca es «ganar por ganar»; sino, en realidad, «ganar para imponerse». Y ello, en términos institucionales, se traduce en la necesidad de contar con un público que sea testigo del desenlace, de la victoria y de la derrota. En las disputas, en realidad, el público no juzga; sólo lo hace en el caso de que no se haya producido un resultado claro. No se olvide que la cuestión no es quién tiene razón, sino quién vence. Igual ocurre en los duelos, los padrinos son vigilantes del cumplimiento de las reglas del duelo-proceso y testigos del desenlace del duelo-resultado. En resumen, hay disputas que no están institucionalizadas (una pelea de pareja); pero la institucionalización de las disputas suele conllevar la presencia de terceros que garanticen los derechos de los contendientes durante la disputa-proceso y que sean testigos del desenlace de la disputaresultado.

La institucionalización de las controversias «pide» también la presencia de terceros. El carácter conflictivo y temático de las controversias dota de sentido a la presencia de un tercero neutral cuyo papel es, por un lado, garantizar que se respeten los derechos de los competidores y, por otro, que se discuta la cuestión controvertida (que no se evada la cuestión). Si bien se considera, este es el papel típico del moderador de un debate. Ahora bien, en las controversias cada interlocutor tiene clara la solución que propone para la cuestión controvertida y, en general, está poco dispuesto a cambiarla. Por ello, el sentido de este tipo de debate no es persuadir al otro (se asume que ambos interlocutores estarán cerrados a los argumentos), cuanto convencer a un(os) tercero(s) que será(n) quien(es) «juzgará(n)» la cuestión. La institucionalización de las controversias reclama el papel de un tercero que juzgue la cuestión controvertida, que evalúe el choque de soluciones incompatibles. Ese tercero puede ser un juez, un tribunal colegiado, el público asistente al debate, etcétera. 
Por el contrario, el rol de los terceros pierde mucho de su sentido en los debates cooperativos. En efecto, en los debates cooperativos institucionalizados puede haber alguien que juegue un papel especial de coordinador o que ejerza de presidente del grupo de debate o algo por el estilo. Pero estos roles especiales o diferenciados no excluyen a quien lo ejerce como interlocutor dentro de ese mismo debate. El coordinador de una sesión clínica es un participante más, no es un tercero neutral. El presidente de un tribunal durante la deliberación es un deliberante más, no un tercero neutral. Estos roles están vinculados con resolver problemas de coordinación y con velar para que el debate sea productivo. La ausencia de conflicto hace superflua en gran medida la figura del tercero neutral que vigile el cumplimiento de las reglas. Además, el carácter cooperativo del debate hace innecesario también el rol de un tercero que sea testigo o que juzgue el resultado del debate. La cooperación rinde sus frutos sin necesidad de que intervengan terceros que den testimonio del resultado o que juzguen quién o qué tesis ha ganado. Ello es así porque en los debates cooperativos todos están llamados a ganar.

\section{A MODO DE CONCLUSIÓN}

Tomando como punto de partida la variable conflicto/cooperación entre los interlocutores y recurriendo a las metáforas, hemos glosado cuatro formas de debatir: «debatir es combatir», «debatir es competir», «debatir es diagnosticar» y «debatir es construir». Ello nos ha permitido caracterizar los siguientes cuatro tipos ideales de debate ordenados desde el máximo nivel de conflicto al máximo nivel de cooperación: la disputa (debate conflictivo y actoral), la controversia (debate conflictivo y temático), el diálogo racional (debate cooperativo y temático) y el consenso (debate cooperativo y actoral). Algunos autores incluyen la negociación como un tipo autónomo de debate (o de diálogo argumentativo) ${ }^{11}$. Sin embargo, aquí hemos evitado incluirla dentro de nuestra escala. La razón es clara: Una negociación puede recorrer cualquier combinación de los modos de debatir arriba destacados. Es decir, puede tener momentos de disputa, de controversia, de diálogo racional y de consenso. Por ello, su introducción en nuestra escala como un modo diferenciado de debatir hubiera reducido de manera drástica el potencial explicativo de la misma. La escala aquí asumida ha sido construida precisamente para poder explicar aspectos importantes de la negociación y de la mediación. Pero de ello nos ocuparemos en otra ocasión.

11 En este sentido, vid., por ejemplo, las notas 5 y 6. 